\title{
Multidimensional Poverty in Côte d'Ivoire: A Measure by the Fuzzy Set Theory
}

\section{Dr Patrick Franklin Kouassi}

Ecole Supérieure Africaine des Technologies de l'Information et de la Communication Abidjan /Côte d'Ivoire

\author{
Anderson Stéphane Seka \\ Université Felix Houphouët Boigny de Cocody Abidjan/Côte d'Ivoire
}

Doi:10.5901/mjss.2017.v8n1p139

\begin{abstract}
Poverty is a complex concept, whose multidimensional aspect in Côte d'lvoire. We rely on the Study of Living Standards (LSMS. 2008) allows us to understand the phenomenon by an approach of fuzzy sets. The results show that by measuring the Multidimensional Poverty Index (MPI) $45.36 \%$ of Ivoirians are structurally poor households in 2008, with differences at the departmental level, the place of residence and gender of household head, and at the nine (9) dimensions. Furthermore, examination of one-dimensional poverty indices by dimension contributing to the state of household deprivation, shows different profiles. This implies that strategies of poverty reduction cannot rely on a single instrument, or to cover a single area, but must use a set of measures affecting its different dimensions.
\end{abstract}

Keywords: Multidimensional poverty, fuzzy set theory, Cote d'Ivoire

\section{Introduction}

The situation regarding poverty and social exclusion remains worrying: in the world. According to estimates of the World Bank (2013), $40 \%$ of the population in Africa live on less than $\$ 1.25$ a day. This fact testifies to the seriousness of the phenomenon led the World Bank to make poverty reduction a priority mission. Also is it set targets in this case to end extreme poverty within a generation and promote shared prosperity. Achieving this goal though certainly require the implementation of bolder policies to promote effective poverty reduction

In its report Overcoming Human Poverty, UNDP (2000), specifically defines the implicit notions such as: extreme poverty, widespread poverty and human poverty. However, the World Bank does not stick to this analysis, it does not fail to evoke the interrelations between the different facets of poverty and explains that the comprehensive study of certain sectors or areas is fundamental to grasp the poverty in its complexity. These areas are health and education, vulnerability (uncertainty and risk particularly affect poor populations), lack of speech and lack of power. To assess these areas, the World Bank reviewed a series of indicators or possible lines of inquiry. It explains and refutes the idea of defining a composite index, however, looking to see how the various areas are combined, reinforce or exacerbate to increase or decrease the state of indigence of a social category.

Beyond these previous approaches, a research project conducted jointly with the Oxford Poverty and Human Development Initiative (OPHI), developed a measuring multidimensional poverty from multiple deprivation indicators. Known as the Multidimensional Poverty Index (MPI), this measure internationally comparable developed by OPHI and the United Nations Development Programme (UNDP) is based on ten indicators on education, health and living standards. It has been applied to about 104 developing countries and published in the global Human Development Report by UNDP since 2010. IPM methodology was developed by Sabina and Foster (2009).

The objective is to determine the scope of a measure of multidimensional poverty in Côte d'Ivoire. Specifically, it will be: to highlight the different dimensions that characterize the phenomenon of multidimensional poverty in Côte d'Ivoire and to show in what terms this specificity of multidimensional poverty in Côte d'Ivoire.

The paper is organized into four sections. The first two present the literature review, focusing respectively on the approach and selection of areas (section 1) and we briefly present the methodology (Section 2). The results will be made in Section 3, followed by the conclusion (section 4). 


\section{Data and Approaches}

The issue of assessment of situations of deprivation and identification of poor individuals raises the threshold of the problem in which the analyst believes that people are poor. As regards multidimensional poverty, both methods can be advanced: the first method called scoring, ( ) is to establish for each indicator and for each domain score and then determine a threshold score between poor and non-poor.

The second method is the sharp distinction between the two groups, and one rather speaks of gradation in the state of poverty. Some authors (Chiaperro-Martinetti, 2007), noted that the use of fuzzy set theory, takes into account the gradation of the state of individual deprivation. As part of the study, we work on the LSMS 2008 in Côte d'Ivoire, where we select the relevant dimensions to build the multidimensional index by fuzzy logic.

\subsection{Analytical approach}

The debate proposed by the central capabilities Nussbaum (2003), demonstrates the difficulty opted for such area rather than another. We therefore accept as variable focal length, a set of operations performed to measure and analyse poverty.

\subsection{Selection fields and variables.}

In this study, we have identified five main areas: Material well-being, Health, Education, Safety and Welfare and nine (9) wellness dimensions (areas education and social welfare are at both field and dimension. the phase of the choice of variables must respond to the desire to take account of socio-economic realities of the country.

Table 1: Characteristics of the areas and dimensions of poverty in Côte d'Ivoire

\begin{tabular}{|c|c|c|}
\hline Fields & Dimensions & Variables \\
\hline 1. Material well-being & $\begin{array}{l}\text { Accommodation }\left(\mathrm{x}_{1}\right) \\
\text { Equipment }\left(\mathrm{x}_{2}\right)\end{array}$ & $\begin{array}{l}\text { - Housing type } \\
\text { - Comfort of the accommodation } \\
\text { - Density per room or person per room } \\
\text { - Access to a water point in housing } \\
\text { - Electronic equipment (tv, fan, air conditioner, refrigerator, freezer) } \\
\text { - landline / mobile phone }\end{array}$ \\
\hline 2. Health & $\begin{array}{l}\text { Access to care and disease }\left(x_{3}\right) \\
\text { Hygiene }\left(x_{4}\right)\end{array}$ & $\begin{array}{l}\text { - Morbidity rate (sickness ratio / household size) } \\
\text { - Problems with access to care? } \\
\text { - Where wastewater is dumped? } \\
\text { - Shower type } \\
\text { - Flushing toilets }\end{array}$ \\
\hline 3. Education & Education $\left(\mathrm{x}_{5}\right)$ & $\begin{array}{l}\text { - Head of household literate? } \\
\text { - Did head of household receive a formation? } \\
\text { - Issues in access to education }\end{array}$ \\
\hline 4. Safety & $\begin{array}{l}\text { Food safety. }\left(x_{6}\right) \\
\text { Financial security }\left(x_{7}\right) \\
\text { Work }\left(x_{8}\right)\end{array}$ & $\begin{array}{l}\text { - Food aid received from parents living elsewhere } \\
\text { - Single meal } \\
\text { - The household borrows money? } \\
\text { - Monetary poverty } \\
\text { - Dependency ratio (non-assets per asset) } \\
\text { - Do you own land? }\end{array}$ \\
\hline 5. Welfare & Social well-being $\left(\mathrm{x}_{9}\right)$ & $\begin{array}{l}\text { - Possessing a means of locomotion? } \\
\text { - leisure spending } \\
\text { - Occupancy status of home (owner?) }\end{array}$ \\
\hline
\end{tabular}

Source: LSMS (2008)

The field of social welfare fits perfectly in the capability approach (2010). This area covers the possibility that possess individuals to freely choose what they value. Thus, the absence of choice is seen as an expression of discomfort, unable to move and access to public infrastructure is seen as a contribution to poverty. So we have identified five major areas of well-being and more detailed analysis brings out new dimensions corresponding to new operations. To evaluate these nine (9) dimensions, we selected 23 variables deemed important to the daily lives of households. 


\section{Methodology}

\subsection{Construction of the multidimensional index by fuzzy logic}

The measurement of multidimensional fuzzy sets of poverty requires the calculation of indices that allows the definition of two concepts namely: economic entities or all of the households in an economic area $\mathrm{A}=\left\{a_{1}, \ldots \ldots a_{i}, \ldots \ldots \ldots, a_{n}\right\}$ a vector $\mathrm{m}$ socioeconomic dimensions selected to study the state of poverty $\mathrm{A}: \mathrm{X}=\left\{X_{1}, \ldots \ldots X_{i}, \ldots \ldots \ldots, X_{n}\right\}$ Call $\mathrm{B}$ a subset of $\mathrm{A}$ fuzzy as each has a degree of deprivation in at least one of the attributes included in $X$. The membership function in the fuzzy set $B$ i-th household $(i=1 ; \ldots \ldots \ldots, n)$ relative to $j$-th dimension $(j=1 ; \ldots \ldots \ldots . ; m)$ is defined as follows:
$\boldsymbol{x}_{\boldsymbol{i j}}: \boldsymbol{\mu}_{\boldsymbol{b}}\left(\boldsymbol{X}_{\mathbf{j}}\left(\boldsymbol{a}_{j}\right)\right)$
$0 \leq x_{i j} \leq 1$,

We have $x_{i j}=1$, If the $i$-th household does not have the $j$-th dimension; $x_{i j}=0$,, if the $i$-th household possesses the j-th dimension. $0<x_{i j}<1$, if the $\mathrm{i}$-th household has partially the j-th dimension. The membership function of the $\mathrm{i}$-th household subset $\mathrm{B}$, measures the multidimensional poverty ratio of the $\mathrm{i}$-th household. This function can be defined as the average weight of $\boldsymbol{x}_{\boldsymbol{i} \boldsymbol{j}}$

$$
\mu_{B}=\frac{\sum_{j=1}^{\mathrm{m}} x_{i j} w_{j}}{\sum_{j=1}^{\mathrm{m}} w_{j}}, 0 \leq \mu_{b}\left(a_{j}\right) \leq 1
$$

$w_{j}$ is the weight attached to the jth dimension. Note that this represents the weight $w_{j}$ deprivation of intensity related to the dimension $X_{j}$. This is an inverse function of the degree of deprivation of this size to the population of $n$ households. The degree of deprivation linked to $X_{j}$ dimension is given for this purpose by: $\frac{\sum_{j=1}^{\mathrm{n}} x_{i j} n_{i}}{\sum_{j=1}^{\mathrm{n}} n_{i .}}$ with $\sum_{i=1}^{\mathrm{n}} n_{i}=n$, $n$ being the total number of households. As the number of private households $X_{j}$. The size is small, and the weight $w_{j}$ will be great. Cerioli and Zan (1990) define a weight that can be written as follows:

$$
W_{j}=\ln \left(\sum_{i=1}^{n} n_{i} / \sum_{i=1}^{n} x_{i j} n_{i}\right) \text { Avec } \sum_{j=1}^{\mathrm{n}} x_{i j} n_{i}>0
$$

Thus, we have: $\mu_{b}\left(a_{j}\right)=0$, if $a_{i}$ has the $\mathrm{m}$ dimensions; $\mu_{b}\left(a_{j}\right)=0$, if $a_{i}$ is totally devoid of $\mathrm{m}$ dimensions; 0 $<\mu_{b}\left(a_{j}\right)<1$, If $a_{i}$ is partially or totally deprived of some dimensions but not totally bereft of all sizes. It gets fuzzy poverty index of the set $\mathrm{A}$ by the following formula:

$$
\mu_{B}=\frac{\sum_{i=1}^{\mathrm{n}} \mu_{b}\left(a_{i}\right) n_{i}}{\sum_{i=1}^{\mathrm{n}} n_{i}}
$$

$\frac{n_{i}}{\sum_{i=1}^{\mathrm{n}} n_{i}}$ is the relative frequency represented by the observation of $\boldsymbol{a i}$ household in the total population of the households.

We can also calculate a one-dimensional index for each $\boldsymbol{j}$ dimensions defining the degree of deprivation of $\boldsymbol{j}$ dimension to the population of households' $n$ :

$$
\mu_{B}\left(X_{j}\right)=\frac{\sum_{i=1}^{\mathrm{n}} x_{i j} n_{i}}{\sum_{i=1}^{\mathrm{n}} n_{i}}
$$

Analysis of the results obtained at the relation (5), for $j=1, \ldots m$, to identify the characteristics of poverty and respond structurally to its reduction. The overall fuzzy poverty index can also be obtained as a weighted average of onedimensional indices for each dimension as follows:

$$
\mu_{B}\left(X_{j}\right)=\frac{\sum_{j=1}^{\mathrm{m}} \mu_{B}\left(X_{j}\right) w_{i}}{\sum_{j=1}^{\mathrm{m}} w_{j}}
$$

\subsection{Treatment Indexes Multidimensional Poverty (I.P.M.)}

To determine that an individual is poor in one dimension, we are the weighted sum of variables (which are dichotomous), we divide by the total weight of the dimension. This gives the rate of completion of the dimension. So to decide if the individual is poor or not in size, comparing the result with a threshold ( $50 \%$ in our case). Thus, for each individual, we have the poverty status ( 1 if declared poor, 0 otherwise) in each dimension, and we make crosses 2 by 2 dimensions $Y_{i}$ 
the variable of interest is a variable taking 1 if the household is poor, 0 otherwise. In the methodology assumes that a household is considered poor in one dimension if he did not meet at least one performance dimension. But this assumption is too strong. We therefore assume that a household is poor if he fails to fulfil $50 \%$ of accomplishments. Clearly, a household is declared poor multi-dimensionally if the individual PMI is above $50 \%$ ( 1 if declared poor, 0 otherwise). With this notation, we can cross the multidimensional poverty with other variables (income poverty, and demographic characteristics of the household).

\section{Results}

In determining the results, we need to control all the variables selected.

\subsection{Control variables}

It is essential to control the selection of variables done a priori. To do this, we will first recode the selected variables in order to capture the degree of deprivation of individuals.

More modality is rare and more it deviates from the average profile. We set a scarcity threshold is a value below which a rare modality is assumed a modality at a frequency below $10 \%$ and above $90 \%$.

Then using the statistical chi-square test us independence between them, for each dimension. If the correlation is low, we conclude that the variables provide additional information to define the dimension. However, correlated variables must be treated differently: if the correlation is strong and significant it will be necessary to eliminate the offending variables since the information conveyed largely overlaps the information conveyed by the other.

The test statistic is given by the formula (7) above:

$x^{2}=\sum_{j=1}^{i} \sum_{j=1}^{c} \frac{\left(A_{i j}-E_{i j}\right)^{2}}{E_{i j}}$ (7)

With: $\boldsymbol{A} \boldsymbol{i} \boldsymbol{j}=$ is the actual frequency in the i-th row and $j$-th column.

$\boldsymbol{E} \boldsymbol{i} \boldsymbol{j}=$ is the expected frequency in the $\mathrm{i}$-th row and $\mathrm{j}$-th column. I = is the number of lines; $c=$ is the number of columns. A lower value of $x 2$ is an indicator of independence. As shown in the formula, the value of $x 2$ is always positive and is 0 when $\boldsymbol{A} \boldsymbol{i} \boldsymbol{j}=\boldsymbol{E} \boldsymbol{i} \boldsymbol{j}$ for every $\mathrm{i}$, j

We, the null hypothesis ( $\mathrm{Ho})$ by default, that the two variables are independent, we reject $\mathrm{H} 0$ if $\mathrm{p}$ is less than 0.05 . This indicates that there is a link between the two variables. The strength of the relationship may be then be demonstrated by the $V$ Cramer. $V>=0.70$ : strong link and $V=0.00$ : null. Before we can test already removed from the list of variables, the variable Vaccination of children under 5 years, to the extent that only $0.03 \%$ of our sample is not concerned. Indeed, if we use a variable whose terms reached a very low frequency of occurrence, it may offer the rarest mode a greater contribution than it is in reality.

\subsection{Breakdown of non-income poverty}

Table 2: Weights of privations by dimensions

\begin{tabular}{|c|c|c|c|c|c|}
\hline Dimension & $J$ & $\mu_{b}\left(X_{j}\right)$ & $\sum_{i=1}^{n} x_{i j} n_{i} / \sum_{i=1}^{n} n_{i}$ & $\begin{array}{l}\text { Weight by dimension (wi) } w_{j}= \\
\quad n\left(\sum_{i=1}^{n} n_{i} / \sum_{i=1}^{n} x_{i j} n_{i}\right)\end{array}$ & $\mu_{b}\left(X_{j}\right)^{*} w_{j}$ \\
\hline accommodation (x1) & 1 & 46,64 & 0,08 & 2,52 & 117,53 \\
\hline Equipment (x2) & 2 & 53,52 & 0,11 & 2,25 & 120,42 \\
\hline $\begin{array}{l}\text { Access to care and } \\
\text { disease }(x 3)\end{array}$ & 3 & 39,76 & 0,11 & 2,19 & 87,07 \\
\hline Hygiene (x4) & 4 & 78,77 & 0,17 & 1,79 & 141,00 \\
\hline Education (x5) & 5 & 46,18 & 0,07 & 2,64 & 121,92 \\
\hline Food safety (x6) & 6 & 16,23 & 0,10 & 2,34 & 37,98 \\
\hline Financial Security (x7) & 7 & 36,71 & 0,15 & 1,93 & 70,85 \\
\hline Work (x8) & 8 & 44,22 & 0,14 & 1,97 & 87,11 \\
\hline Social well-being $(x 9)$ & 9 & 51,79 & 0,08 & 2,48 & 128,44 \\
\hline
\end{tabular}

Source: Authors' calculations with data LSMS [2008]. 
The use of fuzzy logic allows us to decompose the index of well-being in one dimensional index and show the respective weight of each of the selected dimensions. We present this decomposition then interest us further in achieving each of the operations, according to socio demographic characteristics and attributes of the households surveyed. The dimensional indices and the weight of each dimension: $\mu_{B}=\sum_{j=1}^{\mathrm{m}} \mu_{b}\left(X_{\mathrm{j}}\right) w_{j} / \sum_{j=1}^{m} w_{j}$

So $\mu_{B}=\frac{912,32}{20,11}$ is a Multidimensional Poverty Index (MPI) is $45.36 \%$. In other words, $45.36 \%$ of Ivorian households are structurally poor disintegrated in 2008. A review of fuzzy multidimensional poverty index obtained for the Côte d'Ivoire can calculate dimensional poverty indices by dimension contributing to the state of deprivation of households (Table.2). Thus, the analysis of fuzzy indexes dimension of poverty shows that hygiene, equipment, social welfare, housing is at first seen as the main causes of poverty Ivorian households with surrounding and higher rates IPM rate $(45.36 \%)$. Food security has to be the least influential.

When we talk about health in this study, we resorted to the place where are thrown wastewater, used the toilet type and storage of waste. Sanitation is closely related to habitat. The health dimension is the impact the highest with $78.7 \%$ index in our sample. Despite its importance for health, sanitation is not developed in the Côte d'Ivoire. A measure of dimensional poverty, obtained on equipment and housing dimensions shows that the degree of deprivation of the total population of $53.52 \%$ and $46.6 \%$ respectively. The results that we end show that poverty in terms of these attributes is much more widespread in Côte d'Ivoire. Indeed, in housing that portrayed a promiscuous life situation and a screaming need of essential convenience such as the use of electricity and the presence of running water inside the housing.

The elements of comfort and household equipment are also an important dimension to identify their level of poverty. The study of the possession of these items provides insight into the evolution of household living standards. Access to this equipment such as household appliances is strongly related to the degree of well-being experienced by the household. The variable communication is captured by indicators such as household ownership of a TV, radio or telephone. Note that for the overall equipment size deprivation level is important namely $53.52 \%$ within the Ivorian population.

The welfare dimension is also a source of poverty in households with an index of $51.8 \%$. In our study it is manifested by the possession of a means of locomotion. The transport sector has a structuring effect on other sectors of activity and well-being. Indeed, the development of transport infrastructure and services is crucial to boost competitiveness, private investment, opening up.

Health and more precisely the dimension access to care and disease is now considered a component of human capital as well as education, and essential to well-being. Our results show that in this dimension the sample households are heavily affected with almost $40 \%$ of deprivation. This poor score $(0.63 \%$ for access to care and 0.73 for morbidity) should not make us lose sight of the fact that we have not taken into account in the construction of this size, variable directly measuring the data on mortality and child immunization.

The result of the education dimension is $46.18 \%$, allows us to assess the degree of access of the poor to education and training and confirms that illiteracy is more observed in the Ivorian poor. Indeed, the net enrolment rate increased from $56.5 \%$ in 2002 to $56.1 \%$ in 2008 . Overall, the low availability rates observed are related to management difficulties resulting from insufficient reception capacities and poor state of educational infrastructure unevenly distributed across the national territory.

The financial security contributions are $36.7 \%$ is understood here in relation to the financial situation of the household and its expenditure. Through this dimension, the study tries to take into account the monetary dimension of poverty households generally used by many studies to understand the poverty of an individual. It should be noted that this dimension comes in second last position as a contribution to poverty populations showing that monetary poverty among individuals contributes in no small way but weakly to overall poverty of individuals.

In this analysis of the incidence of poverty in the nine dimensions, two observations can be made. First, it is in the dimension of hygiene, equipment, social welfare, housing that poverty affects the majority of Ivoirians. Secondly, deprivation levels are quite high in most dimensions. Thereby revealing that the problem of poverty in Côte d'Ivoire must be at the heart of the concerns of public authorities. Similar results were found in the (DSRP; 2009, 2010).

Furthermore, multidimensional poverty must go through the study of the contribution of each operation to phenomena. The theory of fuzzy sets allows us to calculate the contribution of each function to total poverty. In the table the calculated contributions show that food security dimension is that as a whole contributes least to the impact of household poverty. Indeed, the elements relating to Housing (x1), equipment (x2), Education (x5), and Financial Security (x7) have a relative contribution to Multidimensional Poverty Index dimensions by $13 \%$. The access to care and disease (x3), Labour (x8) have a relative contribution to Multidimensional Poverty Index dimensions by $10 \%$. Hygiene (x4), social well -being $(x 9)$ have a relative contribution to Multidimensional Poverty Index dimensions by $16 \%$. Food Security (x6) 
has a relative contribution of Multidimensional Poverty Index dimensions to $1 \%$.

Moreover, the results on the Multidimensional Poverty Index (MPI) by regions and dimensions reveal quite heterogeneous poverty indices. However, it is possible to decompose the strata analysis. Education and access to care and disease are the dimensions that have a homogeneous configuration and implementation across all regions. At the disaggregated level, we see Abidjan, the central regions, South, and West, North Central are the sites whose indices are highest for access to care and disease. The precarious condition manifests on the entire territory at the health dimension confirming the first observations made previously. Of all the regions except the coastal and central index of education is high at the Ivorian people

Abidjan is the site where the level of poverty is the lowest, all things being equal; a high income level is likely to result in successful completion of the operation related to education. However, the regions that have high deprivation are the consequences of the lack of access to public education services to these areas but especially the poor perception of the usefulness of this dimension in the welfare of households.

It is important to note that the level of food security dimension of poverty index is relatively homogeneous and low for the entire country with the exception of two areas namely the Man region and Bondoukou where the index is notably above the national average of deprivation for the dimension that reaches $30 \%$ and $24 \%$ in its areas. Strong tendency are found with very high composite indices than average northeast, west and northwest for equipment $(80.5 \% ; 77.9 \%$ and $75.2 \%)$ and housing $(65.1 \% ; 57.2 \% ; 60 \%)$. This is to the credit of the precariousness of equipment and poor quality housing in their areas which contribute significantly to poverty populations. However Abidjan, the region of Abengourou and the Bouaké display of the highest deprivation indices in the work dimensions and social welfare either torque respectively, Abidjan (64.4\% -77.4\%), the region Abengourou (50\% - 52.8\%) and Bouaké (50\% - 50\%).

\subsubsection{Poverty measures based on certain characteristics of households}

For non-monetary poverty, it may be appropriate to break down the results according to various socio-demographic characteristics. We focus primarily on the characteristics that are associated with a high risk of deprivation in many dimensions. If the profile only interested in two modalities (eg rural-urban, man -femme etc.), a significant difference of deprivation rate among these groups is also considered as a high or low risk indicator.

First, the distinction by gender of household head shows a significant difference in the state of deprivation. If we take the value of the aggregate index, we find that households headed by women reached a score of 0.47 against 0.43 only for male households. If we break down this indicator depending on the size, there is little inequalities in achievement. Thus, apart from the housing dimension and hygiene to which households headed by men have a significantly higher rating than those headed by women $(0.50$ against 0.44$)$ and $(0.84$ against 0.78$)$ all other dimensions are largely dominated by female households. Women's centers appear multi dimensionally poor than male households. The difference ( 0.06 point) regarding housing and health are not to the advantage of women although we may think that in general women have a better lifestyle than men.

The age of the household head appears somewhat important we in explaining the phenomenon of poverty. Three profiles emerge: (i) a first profile, which can be called down, which includes dimensions welfare indices decline with age. We find in this category, including dimensions related to social welfare and work, both characteristic phenomena of aging. An interesting aspect from the perspective of households headed by older people. This group present a risk of deprivation in five dimensions, but shows that people living in such households are less likely to be denied in the work dimensions and welfare. A plausible explanation for this would be that these households currently have limited monetary resources for consumption but over the life of the head of household, resources have been devoted to acquiring a property to carry a means of transport which improves the well social -being of household members, the same applies to the dependency ratio which is low given that dissaving. (ii) A second profile, ascendant, which includes the dimensions for which the indices increase with age. We find in this category, the education and financial security dimension. The financial security dimension is affected by this phenomenon and reflects the decrease in borrowing, often productive, contracted to carry out professional activities with age, as well as monetary poverty of some evils that the render invalid inactivity and age. For the education dimension, it is arguable that this is a result of educational policies of successive governments that have not made it compulsory education. So for previous generations many illiterate is found within them. Following the crisis, this sector has experienced great difficulties with the suspension of activities of the literacy pilot project (executed 21.12\%) which was experimenting with functional literacy and post-literacy strategies. (iii) $A$ final profile, said $U$ and $V$, which corresponds to the dimensions whose indices values alternate with age. These profiles relate to housing, equipment, and to a lesser extent health. This suggests that age is not a variable that differentiates the level of deprivation between dimensions. 
Household size, reflected indirectly by marital status, represents a significant burden in terms of well-being. We see a first profile, which can be described as ascending, which includes the dimensions for which the indices increase with household size. We find in this category, housing dimensions, education, and financial security. Another profile that can be called down concerning equipment attributes, Health, Labour and Welfare.

Analysis of the results broken down by size allowed us to highlight the importance of the life cycle in which the household is located (through the age of the head and household size), and the status of the household and the gender of the household head. All this shows that a specific group may have specific problems and, therefore, once again provides clear evidence of the interest in the multidimensional approach to poverty that captures the aspects that are unobservable when we uses the single monetary approach.

\subsection{Analysis of Multiple Deprivation}

So far, we have analysed and compared aspects of deprivation to a level one-dimensional clearly, it is intuitively conceivable that high levels of deprivation in dimensions imply the possibility that the Ivorian population private or simultaneously in several dimensions. Anyway, the tables discussed so far have failed to know to what degree certain groups of the population suffers deprivation particular combinations simultaneously. So it is here to be interested in conducting investigations on aspects of simultaneous deprivation experienced by individuals.

Knowing which groups suffering from particular combinations of deprivation is important to the extent that such groups may constitute priority groups for policy makers. Furthermore, deprivation in multiple dimensions may give an indication of the possible relationships between dimensions. For example do not have work can influence the level of consumption of an individual and that education influences the possibility of finding a well-paid job. This leads to think that the solutions tend to reduce deprivation in one dimension may be in another dimension.

The procedure that was followed is this: We analyse how deprivation in one dimension overlap with other dimensions. This part will be done on the general population, but also for gender differences (male, female). The purpose of this analysis is to identify the dimensions in which these interconnections are strong and to what extent it is more likely that these groups are exposed to particular combinations of deprivation.

The method used for the treatment of IPM in the crossing two by two of the dimensions is the following (Annex). To determine if an individual is poor in one dimension, it is the weighted sum of variables (which are dichotomous), which is divided by the total weight of the dimension. This gives the rate of completion of the dimension. So to decide if the individual is poor or not in size, comparing the result with a threshold (50\% in our case). Thus, for each individual, we have the poverty status ( 1 if declared poor, 0 otherwise) in each dimension, and the crossing of 2 by 2 dimensions becomes easier.

The comparison of individual deprivation situations through 9 dimensions is not an easy question. Indeed, a complete analysis theory requires 40320 comparisons between different dimensions (number of permutations for 8 dimensions). Given the constraints of time and resources, we will work to analyse only the interweaving between each pair of the nine dimensions.

The first observation highlights the importance of dimensions; housing, health and social welfare as the main causes of poverty in Côte d'Ivoire situations. Indeed privations are found in the interconnectedness of torque dimension with high deprivation levels. Also nesting highest between dimensions is the torque (housing, sanitation) with $71 \%$ of Ivorian individuals living in private households in terms of hygiene and decent housing. These results converge our first result on the relative contributions of the dimensions to the multidimensional poverty index with nearly $46 \%$ contribution to this triplet. Also there is a homogeneity at the genus level in Côte d'lvoire only a few points of difference to the disadvantage of women.

\subsubsection{Determination of the proportion of households affected by both income poverty and multidimensional poverty}

Recall that the IPM calculated above does not reflect a proportion of poor individuals in dimension, but rather reflects an overall level of failure in meeting household needs.

We saw in the methodology that can be decomposed as the average index of an individual household level breach. It is this individual IPM that will help us determine whether a household is poor not monetarily or otherwise. In the methodology, it was assumed that a household is considered poor in one dimension if he did not meet at least one performance dimension. But this condition is too strong. This is why it is assumed that a household is poor if he fails to fulfill $50 \%$ of accomplishments. Clearly, a household is declared poor monetarily if not its Individual IPM is more than $50 \%$ ( 1 if declared poor, 0 otherwise). With this notation, we can cross the Multidimensional Poverty with other variables 
(income poverty, and demographic characteristics of the household).

Table 3: Proportion of households affected by both non-monetary poverty and income poverty

\begin{tabular}{c|ccc}
\hline & \multicolumn{3}{c}{ Income poverty } \\
\hline & & non poor & Poor \\
\multirow{2}{*}{ Non-monetary poverty } & non poor & $52,4 \%$ & $17,0 \%$ \\
& Poor & $10,5 \%$ & $20,1 \%$ \\
\hline
\end{tabular}

Source: Authors' calculations with data LSMS [2008].

\subsection{Econometric analysis}

We are building a binomial model. Yi the variable of interest is a variable taking 1 if the household is poor, zero otherwise. We regress these variables on the dimensions of the study.

Probit and logit models were estimated pseudo high R-square, or $76.62 \%$ in the logit model and $76.40 \%$ for the Probit. Thus one finds the good explanatory power of the model. However we will develop a test to choose the optimal model. We perform the Hausman test to determine the most appropriate model for this work. Hausman the test leads to rejection of the hypothesis $\mathrm{HO}$ that the logit model is consistent in $\mathrm{H}_{0}, \mathrm{H}_{\mathrm{a}}$ and under. However the model probit meanwhile is efficient only under Ho. So we opt for the alternative hypothesis that the Probit model is inconsistent. Therefore we choose the logit model for interpretation.

Table 4: Estimating the logit

\begin{tabular}{|c|c|c|c|c|c|c|c|}
\hline Dimension & Coefficient & Std. & Erreur. & $\mathbf{Z}$ & $P>|z|$ & $95 \%$ & Effets marginaux \\
\hline Social well-being & 1,213 & 0,087 & 14,02 & 0,000 & 1,043 & 1,382 & 0,1932223 \\
\hline work & 2,272 & 0,291 & 7,77 & 0,000 & 1,702 & 2,844 & 0,2325524 \\
\hline Financial Security & $-4,962$ & 0,570 & $-8,72$ & 0,000 & $-6,077$ & $-3,846$ & $-0,2257071$ \\
\hline Food safety & $-0,960$ & 1,011 & $-0,95$ & 0,342 & $-2,942$ & 1,021 & $-0,0365721$ \\
\hline Education & $-11,098$ & 410,8 & $-0,03$ & 0,978 & $-816,2$ & 794,1 & $-0,2995273$ \\
\hline Hygiene & 2,799 & 0,094 & 29,88 & 0,000 & 2,616 & 2,983 & 0,1220036 \\
\hline Access to care and disease & $-2,723$ & 0,195 & $-13,99$ & 0,000 & $-3,104$ & $-2,341$ & $-0,1051471$ \\
\hline Equipment & 2,273 & 0,291 & 7,81 & 0,000 & 1,702 & 2,843 & 0,0710375 \\
\hline accommodation & 11,716 & 410,8 & 0,03 & 0,977 & $-793,4$ & 816,91 & 0,3332267 \\
\hline Constant & 14,46 & 1,912 & 7,56 & 0,000 & 10,71 & 18,20 & \\
\hline
\end{tabular}

Source: Authors' calculations with data LSMS [2008].

Given the p-value of our logit model size financial security, education and housing do not have a significant effect on being multi dimensionally poor. Working size, hygiene, equipment, and social well-being tend to influence the probability of being poor.

In previous regressions, we just tried to determine which factor has a positive influence on the probability of being poor . However we have not quantified the effect of explanatory variables on poverty. This approach uses marginal effects which measure the sensitivity of the probability of the event $y_{i}=1$ relative to changes in the explanatory variables $x_{i}$, so an idea of the likely contribution of each explanatory variable to the phenomenon of poverty.

Student Statistics The values are used to specify the significance or otherwise of each of the coefficients. It is common practice and there we refer in this case, to rule on the significance of a coefficient from the $p$ - value. In all that follows, and the results given in the table above, the main determinants of multidimensional poverty in Côte d'Ivoire are perfectly identified.

Thus, the results indicate that education is an important factor in defining the status of poverty. However, the coefficient of this modality is not significant. Having provided a level of education rather than being without level does not reduce the likelihood of becoming poor. The significant coefficients are the working dimensions, equipment, health and social welfare.

Regarding the labour dimension, the statistics recorded in the table show the significance of the coefficient. The estimated value of this variable coefficient is positively related to poverty. So it appears that the standard of living of 
individuals increased by 0.23 units for a decrease of a unit of work in deprivation. Thus, the work is a very important dimension in the analysis therefore in poverty reduction.

The dimension of social well-being determines the ability of individuals to freely choose what they value. The predicted value of this dimension is significant and positive. Indeed it shows that an increase of one this deprivation increases the probability of being poor by 0.19 units. The quality of the living environment of poor households can be affected by nuisances such as noise or pollution, by problems such as vandalism, and which truly compromise their social well-being.

The equipment dimensions and hygiene are important. The resulting marginal effects indicate that the probability that a household out of poverty is 0.07 and 0.12 respectively. Indeed a unit increase of deprivation equipment increases the probability of being poor by 0.07 units. And an increase of one unit of the hygiene deprivation increases the probability of being poor by 0.12 units.

\section{Conclusion}

The complexity of the phenomenon of poverty requires an approach that is able to help assess the situation of individuals in various dimensions of well-being. It is in this perspective that the capability approach, based on a conception of the poor as an individual or household deemed important in operations and responds to the need to recognize that poverty is multi-dimensional, was privileged in this study. It consisted, under the constraints of the availability of information on the basis of 2008 data LSMS households in Côte d'Ivoire to assess the situation of the household in terms of deprivation in nine dimensions of well-being that is the size housing, equipment size, dimension Access to care and diseases, Hygiene dimension, the dimension education, food security dimension, financial security dimension, the dimension and the dimension Work Although social -being

The analysis in this chapter has limits since multiple dimensions have forced us choices. We have motivated these choices but it is clear that there are many more opportunities for deepening understanding of phenomena. This is where even Sen never wanted to provide a list of capabilities or central operations to justify the incompleteness of his theory. However, the extension proposed by Naussbaum (1999) in particular, lets agree on the basis of a list of operations performed by referring to the list of essential requirements defended by advocates of the approach (Stewart, Streeten 1981). We opted for this theoretical position, arguing that the universalism of the list does not foreclose to be adaptable to each context in terms of social and cultural norms of the society studied as ours.

The results we have achieved highlight several aspects. It appears that the Multidimensional Poverty Index and reflects an overall level of failure in meeting the needs of households is $45.36 \%$. From one-dimensional indices and weights for each dimension, we have established that the main dimensions in which the Ivoirians are the most vulnerable to poverty are hygiene, equipment, social welfare and labour. The breakdown by region shows that north central populations are plagued by poverty. The analysis in terms of gender shows a very small difference between the two groups considered. The analysis of poverty according to place of residence is clearly to the disadvantage of rural areas that displays the highest rates in deprivation, except food security. Regarding the breakdowns by group and attribute, we observe that the deprivation rate change from one group to another. This means that the intensity of the phenomenon is heterogeneous within each group, depending on the size considered.

The results show the interest of studies on various aspects contained in the phenomenon of poverty in Côte d'Ivoire. This methodological research should nevertheless lead to dig several avenues of research. Our results are only valid on the limited sampling of 2008 , it would be necessary to extend the analysis of the latest data by integrating variables $\mathrm{y}$ to highlight other aspects.

\section{References}

Banque Mondiale 2001, Combattre la pauvreté, Eska, Paris. Rapport sur le Développement dans le monde 2000/2001.

Banque Mondiale 2012, The On-Line Tool for Poverty Measurement Developed by the Development Research Group of the World Bank, Banque mondiale, Washington.

Banque mondiale 2013, Indicateurs du développement dans le monde (base de données), http://databank.worldbank.org/data/home.aspx.

Foster J., Greer J. et Thorbecke E., 1984, « A Class of Decomposable Poverty Measures », Econometrica, vol. 52, n 3, p. 761-766.

Nussbaum M., 2003, Beyond the Social Contract: Capabilities and Global Justice. Colloque International sur les Capabilités, D'un développement viable à une liberté durable, 6-10 Septembre, Université de Pavie.

Nussbaum M., 2006, Frontiers of Justice, Disability, Nationality, Species Membership. Harvard: Harvard University Press, 487 p.

PNUD 2000 Dans le rapport : Vaincre la pauvreté humaine. 
PNUD 2004, Rapport National sur les Objectifs du Millénaire pour le Développement, Côte d'ivoire.

Sabina A. 2005, Dimensions of Human Development, World Development, vol. 30, n².

Sabina Alkire and James Foster Counting and Multidimensional Poverty Measurement December 2009? OPHI WORKING PAPER NO. 32

Sabina A. et Santos M 2014. Mesure aiguë de la pauvreté dans le monde en développement: Robustesse et Portée de la pauvreté multidimensionnelle Index. Développement dans le monde.

Sabina A. and Foster J., 2011, Counting and multidimensional poverty measurement, Journal of Public Economics, OPHI working paper Paper, $n^{\circ} 95$, Université d'Oxford

Sen A., 2010, L'idée de justice, Paris, Le Seuil ; 1993, Éthique et économie, Paris, Presses universitaires de France (Puf).

Sen, A., 1999 L'Economie est une science morale, Paris : La Découverte, $125 \mathrm{p}$.

Sen, A., 1997, Empowerment as an approach to poverty, Harvard Working paper series, vol. 7, $n^{\circ} 97,25 \mathrm{p}$. 